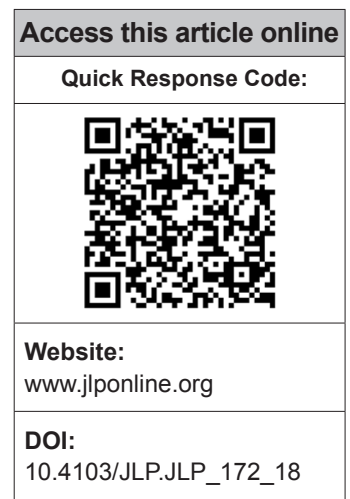

Department of Pathology, Military Hospital, Nasirabad, Rajasthan, ${ }^{1}$ Department of Pathology, Armed Forces Medical College, ${ }^{2}$ Department of Hematology, Command Hospital (SC), Pune, Maharashtra, India

Address for correspondence: Dr. S. Venkatesan, Department of Pathology, Armed Forces Medical College, Pune - 411 040, Maharashtra, India. E-mail: Itcolsvenkatesan@ gmail.com

Submission: 28-12-2018 Accepted: 31-05-2019

\title{
Plasma cell neoplasm with varied morphology: A report of two cases
}

\author{
Gautam Kumar Vasnik, S. Venkatesan', Sanjeevan Sharma², Ajay Malik
}

\section{Abstract:}

Plasma cell $(\mathrm{PC})$ neoplasm $(\mathrm{PCN})$ with varied morphology has been described in the literature. The majority of clonal proliferation of PCs is composed of easily recognizable morphology in the bone marrow (BM). However, few cases may cause diagnostic complexity, as they exhibit varied cytological and architectural heterogeneity which may pose problem in morphological diagnosis and require the use of ancillary techniques like immunohistochemistry $(\mathrm{IHC})$. We illustrate here two such cases of PCN with varied morphology in BM aspirate, in the form of clustering/rosetting and multiple clear cytoplasmic vacuoles, respectively, leading to varied differential diagnosis. However, later, the histopathological features on BM biopsy findings were relatively characteristic and $\mathrm{IHC}$ confirmed the final diagnosis. The morphological variants documented in both these cases are exceptional and representative of the various forms of atypical PCs.

Key words:

Bone marrow, immunohistochemistry, morphology, plasma cell neoplasm

\section{Introduction}

Plasm lasma cell (PC) neoplasm (PCN) including multiple myeloma (MM) patients present with a characteristic presentation like bone pain and other nonspecific symptoms, such as weakness, malaise, and weight loss. The diagnosis is mostly confirmed by the bone marrow $(\mathrm{BM})$ evaluation along with radiological, immunological, and biochemical tests. A wide range of cytological appearances of PCs in BM are well known and have been described in the literature. These comprise of flame cells, Mott cells, thesaurocytes, Russell bodies, and Dutcher bodies. ${ }^{[1]}$

In minority of cases, cytological variations such as polymorphous variant (cleaved, multilobated, and monocytoid cells), blastic variant, small cells variants, anaplastic variant, signet-ring cells variant, histiocytoid cells variants, clear cells variant, spindle cells variants, oncocytic type,

This is an open access journal, and articles are distributed under the terms of the Creative Commons Attribution-NonCommercial-ShareAlike 4.0 License, which allows others to remix, tweak, and build upon the work non-commercially, as long as appropriate credit is given and the new creations are licensed under the identical terms.

For reprints contact: reprints@medknow.com
Burkitt-like morphology, and mimicking erythrophagocytosis are illustrated in literature. ${ }^{[1-5]}$ The other rare cytological variation in PCN is PC satellitism, clustering/ rosette formation around macrophages. ${ }^{[6,7]}$ These atypical morphological variants are extremely difficult for interpretation by pathologists, especially when they are accompanied by unusual clinical presentations and when BM study being done for remission status during the course of chemotherapy. Immunohistochemistry (IHC) and flow cytometry (FCM) immunophenotyping studies are ancillary techniques used for diagnosis and prognosis of PCN in tissue sections and BM aspirate/peripheral blood, respectively. IHC using markers such as CD138 and CD 38 together with $k$ and $\lambda$ light chains and immunoglobulin heavy chains are useful.

\section{Case Reports}

\section{Case 1}

A 72-year-old male presented with breathlessness, on and off low-grade fever,

How to cite this article: Vasnik GK, Venkatesan S, Sharma S, Malik A. Plasma cell neoplasm with varied morphology: A report of two cases. J Lab Physicians 2019;11:281-3. 
backache, and weakness of 1-month duration. Examination revealed pallor and mild hepatosplenomegaly. Examination of other systems was unremarkable.

\section{Case 2}

A 70-year-old female, a known case of MM treated with bortezomib, lenalidomide, and dexamethasone protocol, presented with generalized body ache of 1-month duration. General examination revealed pallor. There was no organomegaly. Other systemic examination was unremarkable.

\section{Laboratory investigations}

Case 1 complete blood count (CBC) showed pancytopenia and peripheral blood smear (PBS) examination showed normocytic normochromic anemia. Hypercalcemia and high levels of immunoglobulin G, proved to be monoclonal by serum immunofixation, were also noted. No lytic lesions were seen in radiological investigations.

BM aspirate showed a cellular marrow, predominated by PCs with large eccentric nuclei, and prominent nucleoli. Most of the PCs formed distinct clusters / rosettes, with tapered basophilic cytoplasmic projections directed toward centrally located macrophage mimicking metastatic carcinoma of unknown primary origin [Figure 1a]. BM biopsy showed hypercellular marrow with sheets of neoplastic PCs [Figure 1b]. IHC showed strong positivity for CD138 [Figure 1c].

Case 2 CBC showed pancytopenia and PBS showed normocytic normochromic anemia. Rest of the investigations was within normal limit.

BM aspirate showed a cellular marrow, predominated by atypical cells with multiple clear cytoplasmic

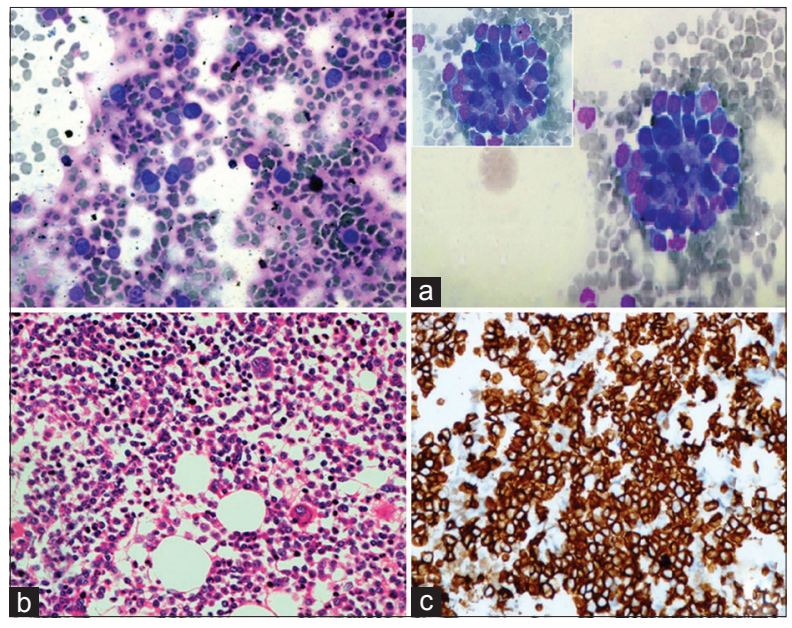

Figure 1: (a) Bone marrow aspirate smear, upper left image $(\times 100)$ and upper right image $(\times 400)$ : Scattered plasma cells throughout the aspirate and clusters of plasma cells forming rosettes (plasma cell satellitism). (b) Lower left image $(\times 400)$ : Hypercellular marrow and marrow spaces show near total replacement by sheets of plasma cells. (c) Lower right image (×400): IHC: CD138-positive plasma cells vacuoles mimicking metastatic deposits of clear-cell carcinoma/histiocytes with vacuolated cytoplasm [Figure 2a]. BM biopsy showed hypercellular BM with sheets of atypical cells with clear cell morphology [Figure 2b]. IHC performed showed strong positivity for CD138 [Figure 2c]. In both cases, the neoplastic cells were positive for CD38, showed kappa light chain restriction and were negative for pan-cytokeratin.

\section{Discussion}

Diagnosis of most of the cases of PCN may not be a problem; however, establishing a precise diagnosis in the presence of unusual clinical findings and cytological and/or architectural features may be challenging at times. It is the cytological aberration than architectural variation that usually leads to an erroneous diagnosis in the BM. These variations are more commonly observed in cases of PC leukemia. ${ }^{[4]} \mathrm{BM}$ evaluation in both these cases showed varied morphology leading to a wide range of differential diagnosis including distant metastasis and histiocytosis. BM aspirate in the first case showed clustering/rosetting of PCs around macrophages (PC satellitism) which has been reported in the past with PCN in association with amyloidosis. ${ }^{[8]}$ It is essential to distinguish this rare morphological finding from other conditions, such as erythroid colony or metastatic carcinoma exhibiting rosette formation to prevent confusion or wrong diagnosis. The second case is a known case of PCN on chemotherapy showing clear vacuolated cytoplasm which is confused with conditions such as Non-Hodgkin's lymphoma with Burkitt-like morphology, histiocytic lesion, Gaucher cells, and inclusion bodies. The molecular basis or posttherapeutic

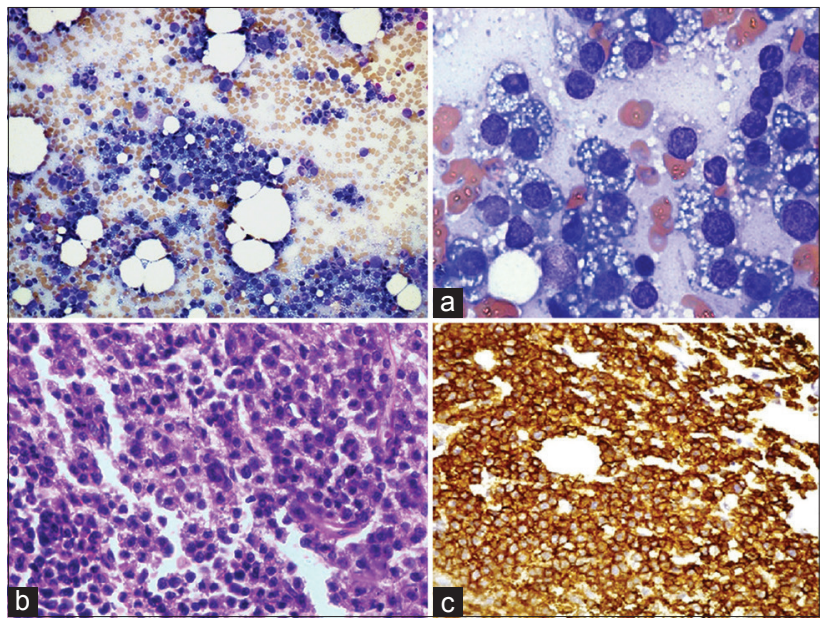

Figure 2: (a) Bone marrow aspirate smear, upper left image $(\times 100)$ and upper right image $(\times 400)$ : Plasma cells with multiple clear cytoplasmic vacuoles seen throughout the aspirate (b) Lower left image $(\times 400)$ : Hypercellular marrow with diffuse involvement of vacuolated cells. (c) Lower right image ( $\times 400)$ : IHC: CD138-positive plasma cells 
effects for such vacuolated appearance of cytoplasm of $\mathrm{PC}$ is not very clear. ${ }^{[9]}$ However, a recent article published by Pandey et al. ${ }^{[10]}$ suggests that the cytoplasmic vacuolization in the myeloma cells are the autophagic vacuoles due to the excessive production of misfolded immunoglobulins.

PCN can also mimic histologically with hematolymphoid malignancy like lymphoma and leukemia, carcinomas like germ-cell tumors, and rarely sarcomas and histiocytic disorders. The clue to the correct diagnosis is finding PCs with typical morphology. ${ }^{[2,3]}$ We conclude here that PCN with varied morphology could be difficult for the pathologist. However, the histopathological features on $\mathrm{BM}$ biopsy findings are often characteristic of PCN and hence along with immunophenotyping by IHC or FCM would aid in arriving at a definite conclusion. A high index of suspicion, clinical association, and awareness of such variations and availability of ancillary techniques in addition to knowledge of rare morphological features are essential to confirm the diagnosis.

\section{Declaration of patient consent}

The authors certify that they have obtained all appropriate patient consent forms. In the form the patient(s) has/have given his/her/their consent for his/her/their images and other clinical information to be reported in the journal. The patients understand that their names and initials will not be published and due efforts will be made to conceal their identity, but anonymity cannot be guaranteed.

\section{Financial support and sponsorship} Nil.

\section{Conflicts of interest}

There are no conflicts of interest.

\section{References}

1. Swerdlow SH, Campo E, Harris NL, Jaffe ES, Pileri SA, Stein H, et al. WHO Classification of Tumours of Haematopoietic and Lymphoid Tissues. Revised $4^{\text {th }}$ ed. Lyon, France: IARC Press; 2017.

2. Banerjee SS, Verma S, Shanks JH. Morphological variants of plasma cell tumours. Histopathology 2004;44:2-8.

3. Lorsbach RB, Hsi ED, Dogan A, Fend F. Plasma cell myeloma and related neoplasms. Am J Clin Pathol 2011;136:168-82.

4. Dadu T, Rangan A, Handoo A, Bhargava M. Primary non-secretory plasma cell leukemia with atypical morphology - A case report. Indian J Hematol Blood Transfus 2009;25:81-3.

5. Gupta R, Hussain N, Rahman K, Nityanand S. Plasma cell myeloma with unusual morphology - a series of 6 cases. Eur J Haematol 2014;93:165-70.

6. Wong KF, Chan JK, Chu YC. Multiple myeloma with tadpolelike cells and rosette formation. Am J Clin Pathol 1992;98:630-2.

7. Dimov ND, Zynger DL, Peterson LC. Plasma cell satellitism in plasma cell myeloma. J Clin Pathol 2006;59:1003.

8. Pillay TS, Sayers G, Bird AR, Jacobs P. Plasmacyte-reticulum cell satellitism in multiple myeloma associated with amyloidosis. J Clin Pathol 1992;45:623-4.

9. Ribourtout B, Zandecki M. Plasma cell morphology in multiple myeloma and related disorders. Morphologie 2015;99:38-62.

10. Pandey V, Khatib Y, Khade AL, Pandey R, Khare MS. Clear cell myeloma artefactual or real. Indian J Pathol Microbiol 2018;61:159-61. 